\title{
Harvesting Electrical Energy from Rooftop Ventilator
}

\section{Khai Xin Lau ${ }^{1}$, Pei Ling Leow ${ }^{2}$, Jasrul Jamian Jamani ${ }^{3}$, Rashidah Arsat ${ }^{4}$, Amr Ahmed Abdelsattar Abdeltawab ${ }^{5}$, Syed Salman Rahman ${ }^{6}$, Nur Hafizah Abd Khalid7, Azman Mohamed ${ }^{8}$, Ismayuddin Abd Khalid ${ }^{9}$}

\author{
${ }^{1-8}$ Faculty of Biosciences and Medical Engineering, Universiti Teknologi Malaysia, 81310 Skudai Johor, Malaysia \\ ${ }^{9}$ Khalid Latiff Holding Sdn Bhd, Jalan Kerinchi, 59200 Kuala Lumpur
}

Received 25 January 2018; accepted 6 June 2018, available online 6 August 2018

\begin{abstract}
Development of the renewable energy is one of the most challenging issue in Malaysia since the fossil fuels and natural gas is foresee to be depleted in one day. Renewable energy is able to provide sustainable yet clean energy to the country in the near future. Other than Solar, wind energy is only of the renewable energy that has the potential to provide green energy to not only domestic but industrial users. This paper proposes a development of similar concept of wind energy by harvesting electrical energy from rooftop ventilator. Modification is made on a commercial rooftop ventilator with an integration of a $120 \mathrm{~V}$ DC motor and conversion gear (gear ratio 1:2) to the turbine shaft. The continuous rotation of the rooftop ventilator due to temperature difference indoor and outdoor rotated the rotor of the DC generator. The DC energy is stored in the battery via a charge controller before distributing to the load. An average of $60 \mathrm{rpm}$ turning speed of the ventilator is simulated mimicking the general turning speed of the ventilator installed on the roof. The generated energy characteristics study is carried out by using standard fan to produce steady rotational of the ventilator. As the spin rate is very low to reach the optimum spin rate, the generated energy is small and only for a small DC load.
\end{abstract}

Keywords: Renewable energy, wind energy, rooftop ventilator, kinetic energy, sustainable

\section{Introduction}

Renewable Energy Sources (RES) and power conversion methods seek attention significantly due to the increasing demand of energy[1]. Malaysia is one of the fastest-industrializing countries and gross domestic product (GDP) that measured the economic growth in Malaysia is proportional to the electricity demand [2]. The electricity demand in Malaysia increases throughout the years and based on annual growth rate of $4 \%$, the electricity demand is expected to reach $23,099 \mathrm{MW}$ in 2020 [3]. The Malaysian energy sector is highly dependent on non-renewable source of energy such as fossil fuel and natural gas. In the long term, the depletion of the remaining natural resources and pollution issues are worrisome. Therefore, renewable energy is important to ensure national energy security, sustainable living and environmental friendly [4]. There are various renewable energy options which are clean and sustainable such as wind, biomass, solar, hydroelectric, municipal waste and biogas that can be explored [5].

Malaysian government has recognised the great impact of these emerging technologies and has put tremendous effort to initiate researches on renewable energy and green technologies. A statutory body such as the Sustainable Energy Development Authority of Malaysia (SEDA Malaysia) was also formed to administer and manage the implementation of the feed-in tariff mechanism which is mandated under the Renewable Energy Act 2011 [Act 725] in Malaysia. Table 1 shows the renewable energy generated in Malaysia.

Table 1 The renewable energy in Malaysia[3]

\begin{tabular}{cc}
\hline Renewable Energy & Potential (MW) \\
\hline Hydropower & 22,000 \\
Biomass/biogas & 1,300 \\
(oil palm mill waste) & \\
Mini-hydro 500 & 500 \\
Municipal solid waste & 400 \\
Solar PV & 6,500 \\
Wind Low wind speed & Low wind speed \\
\hline
\end{tabular}

Sources: Malaysia Energy Centre's National Energy Balance.

In Malaysia, hydropower is the highest energy generation that supports the energy usage.

Currently, energy usage becomes one of the main concerns of local broiler industry as it is used to maintain optimum temperature of the barn and to supply water to the broiler. The common challenges for Malaysian broiler farmers is the ambient temperature, as Malaysia is a tropical country that has the annual temperature range from $24{ }^{\circ} \mathrm{C}$ to $38^{\circ} \mathrm{C}$. The broiler house is normally built on top of the hill and the temperature during day time rises the indoor temperature of broiler house and chill at night. 
Broiler at younger stage required average heat of $35^{\circ} \mathrm{C}$ and at adult stage need to be below $29{ }^{\circ} \mathrm{C}$. This temperature control within the barn consumes enormous energy. The main issue faced by the Malaysia broiler farms is the uncontrolled heat accumulated within the broiler house causes a lot of heat related problem such as heat stroke of broilers that cause death to the broiler. Indirectly this will increase the cost of the broiler. To ensure good ventilation and low temperature in the barn, rooftop ventilators are normally installed at the barn. The rooftop ventilators rotate when there is pressure difference between indoor and outdoor due to temperature difference. The rotation of the ventilator is often at a steady speed, therefore by integrating wind energy techniques to the rooftop ventilator, it can ensure good ventilation and at the same time generate energy [6][7]. The modification of the rooftop ventilator to mimic wind turbine generator can provide partial energy supply to the broiler house [8][9].

The objective of this study is to develop energy harvester system for rooftop ventilators by integrating wind turbine technology. Subsequently, it can support partial loads of the barn house to reduce the energy utilities. This paper discusses the development of the rooftop ventilator for energy harvesting and the electricity generation on small DC load.

\section{Design concept}

The main components of the design concept consists of the rooftop ventilator, DC generator, gearing system for movement conversion, and DC-DC step up conversion to boost up the voltage and to maintain a steady voltage output to supply the DC load such as LED light bulb. Fig. 1 shows the block diagram representation of overall system.

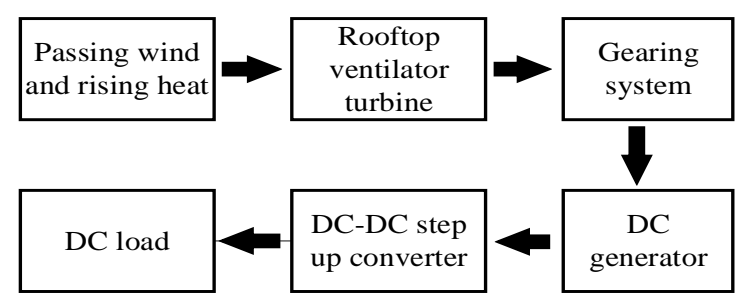

Fig. 1 The block diagram of the overall system

\subsection{Rooftop ventilator}

The rooftop ventilator is widely used in industrial buildings and domestic housing to ventilate the air inside the buildings for better air extraction. The ventilator starts to spin if there is wind pass through the wind blade of the ventilator and from heat accumulated inside the building. The diameter of the rooftop ventilator is 16 inch and consists of 21 fins to capture the wind kinetic energy and rotate. For residential, the diameter of rooftop ventilator ranging from 10 inch to 16 inch while for industrial the diameter ranging from 17 inch to 30 inch. The number of wind blade depends on the size of the ventilator. Fig. 2 shows a typical commercial rooftop ventilator. The rooftop ventilator is manufactured by using high quality stainless steel material which is strong and durable. The ventilator is mimicking the same concept of vertical axis wind turbine to generate electricity, however the process to generate electricity from the ventilator is not straight forward. Therefore this study includes the modification of the rooftop ventilator to generate electricity.
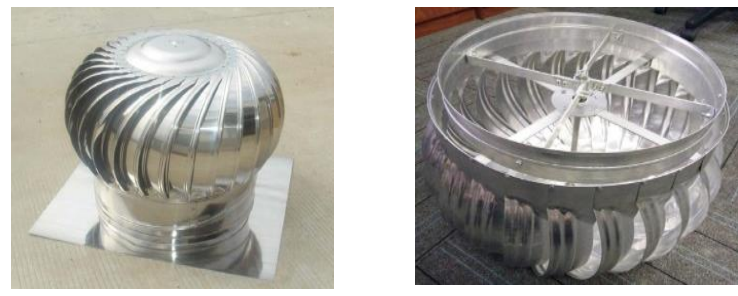

Fig. 2 Physical and inside view of rooftop ventilator

\subsection{DC generator}

A generator converts the mechanical energy into electrical energy. A permanent magnet DC motor is used in this design for generating electricity. The permanent magnet DC motor can produce a maximum voltage at $120 \mathrm{~V}$ with current $0.5 \mathrm{~A}$. The maximum rotational speed of this motor is at $2500 \mathrm{rpm}$ and the power produced is less than $55 \mathrm{~W}$. The specification the permanent magnet DC motor is tabulated in Table 2 .

Table 2 Specifications of the DC motor.

\begin{tabular}{cc}
\hline Parameter & Specification \\
\hline Type of DC Motor & Permanent Magnet DC \\
& Motor \\
Maximum Voltage & $120 \mathrm{~V}$ \\
Maximum Current & $0.5 \mathrm{~A}$ \\
Rotation & Clockwise \\
Revolution Per Minute & $2500 \mathrm{RPM}$ \\
(RPM) & \\
Power & Less than 55 W \\
\hline
\end{tabular}

The overall dimension of the permanent magnet DC motor is shown in Fig. 3.

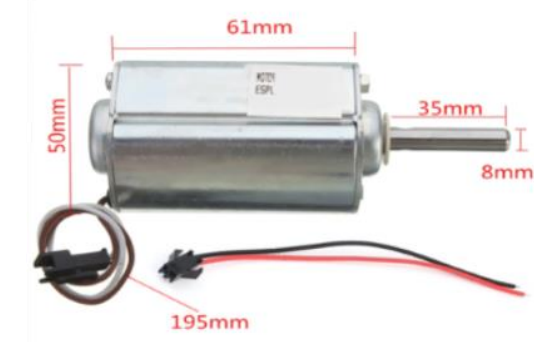

Fig. 3 The dimension of the DC generator 
DC Motor has low starting torque capability to avoid any additional torque that slows down the rotation of the ventilator. The construction of the Permanent Magnet DC Motor is the same as a generator which consists of a stator and a rotor. The permanent magnets are mounted inside the steel cylinder which is the stator. The rotor of the Permanent Magnet DC Motor is made up of the cores, windings and several segments of commutator.

\subsection{Conversion Gear}

The electrical energy is harvested from the rooftop ventilator by converting the kinetic energy from the rotation of the ventilator to electrical energy. Conversion gear is designed to integrate the DC generator to the ventilator. The conversion gear with ratio $1: 2$ is mounted on the bearing disc of the ventilator. Fig. 4 shows the drawing of the conversion gear.

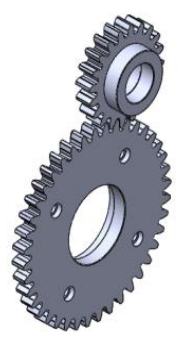

Fig. 4 The conversion gear

The center shaft of the ventilator is static and is connected to a disc bearing. The conversion gear is integrating the bearing disc to the DC generator shaft. The gears are fabricated by using 3D printing method. The gear is mounted on the bearing using screws and grease is applied to the gears to reduce friction. The conversion gear produces double the rotation speed of the generator shaft. Fig. 5 shows the installation of the conversion gear and the DC motor as the generator to the ventilator.

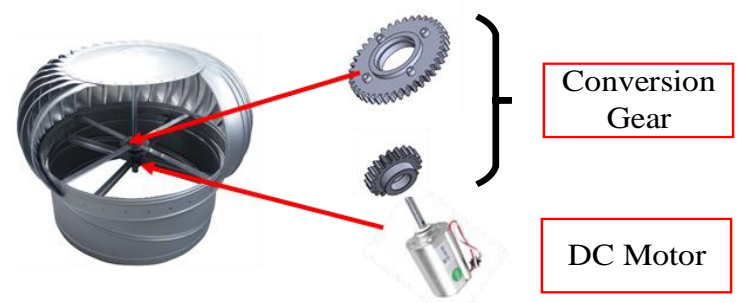

Fig. 5 The attachment of the movement gear and DC motor into rooftop ventilator

A supporting rig is mounted on the support base of the ventilator to hold the DC motor in place.

\subsection{DC-DC Converter Step Up Boost Module with USB}

A DC-DC Converter is used to boost the DC output voltage from the generator. The DC-DC step up converter also used to maintain a steady voltage output to supply the DC load such as DC bulb. The input voltage of this stepup module ranging from 0.9 - $5 \mathrm{~V}$ produced a stable output of $5 \mathrm{~V}$ with maximum current of $600 \mathrm{~mA}$ for supplying small DC loads. The output mode of this module is standard USB which can be used for power up $5 \mathrm{~V}$ USB LED bulb, charging for mobile phone, camera, and many digitals device. Table 3 shows the features and specification of the DC-DC converter.

Table 3 Features of the DC-DC step-up module.

\begin{tabular}{cc}
\hline Features & Specifications \\
\hline Input voltage & $0.9-5 \mathrm{~V}$ \\
Output voltage & $600 \mathrm{~mA}$ \\
Efficiency & Up to $96 \%$ \\
Switching frequency & $500 \mathrm{KHz}$ \\
Voltage indication & LED lights with a load \\
Operating Temperature & Industrial (-40 Celsius to +85 \\
& Celsius) \\
Full load temperature rise & $30^{\circ} \mathrm{C}$ \\
Load regulation & $\pm 1 \%$ \\
Voltage regulation & $\pm 0.5 \%$ \\
Output Mode & Standard USB \\
\hline
\end{tabular}

The output of the DC generator is connected to the input of DC-DC Step-Up Module and the output of the DC-DC Step-Up USB Module is connected to the load. Fig. 6 shows the converter circuit for the electrical charging.

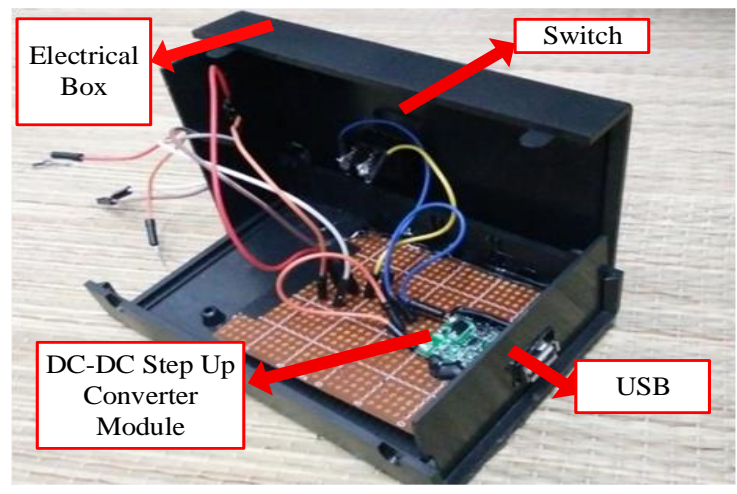

Fig. 6 The connection of the electrical part inside the electrical box

The function of the DC-DC converter is to ensure sufficient power is supplied to the load.

Fig. 7 shows the overall setup of the rooftop ventilator with the energy harvesting system. 


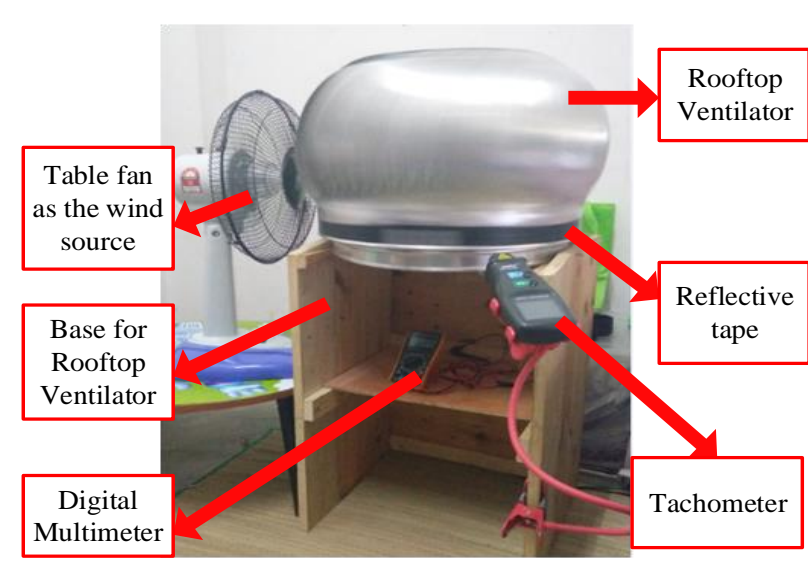

Fig. 7 The experimental setup

A normal fan with three speeds is used to turn the turbine at consistent spin. A tachometer is used to measure the spin rate of the turbine.

\section{Experiment and Results}

The characteristic of the permanent magnet motor as the generator and the system was conducted. For the characterization of the generator, the rooftop ventilator is rotated manually to determine the relationship between ventilator rpm and the generated voltage. The digital laser tachometer is used to measure the ventilator rpm. A reflective tape is used to allow full cycle rotation of the turbine to be detected by the light beam from the tachometer. The output of the generator is connected to the digital multi-meter to display the voltage. Fig. 8 shows the average generated voltage versus the shaft rotation.

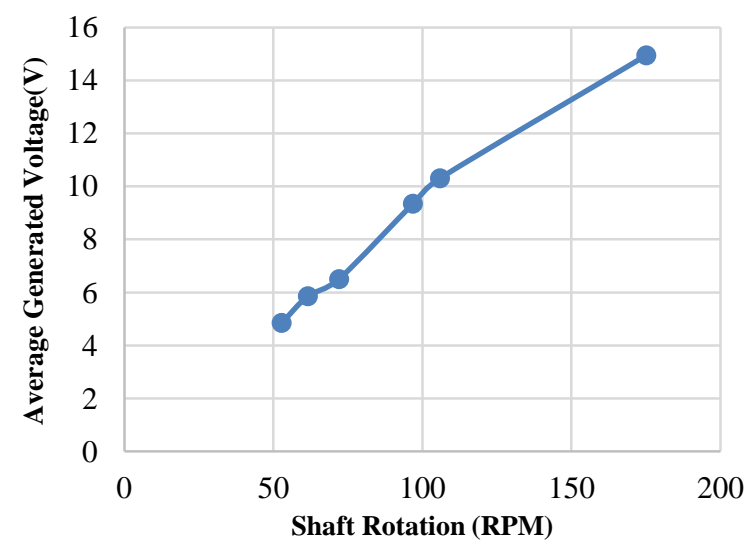

Fig. 8 Average generated voltage versus turbine rotation

From the result, it shows that the lowest rpm which is $52.8 \mathrm{rpm}$ can generate the average voltage of $4.85 \mathrm{~V}$ and at $175.2 \mathrm{rpm}$ it can generate the average voltage of $14.94 \mathrm{~V}$. These results are represented in the form of graph to determine the relationship between the ventilator rpm and the generated voltage. From the graph, it shows the linear relationship between the generator shaft $\mathrm{rpm}$ and the generated voltage. From this plot, when the rpm increases the generated voltage also increases. The higher the rotation speed of the ventilator, the higher the generated voltage. The result verified the linear relationship between the generator shaft rpm with the generated voltage.

A commercial stand fan is used to produce consistent air flow to the turbine for consistent rotations. The ventilator turbine is placed at a fix distance of $15 \mathrm{~cm}$ from the table fan. The table fan is switch 'ON' and speed set 1 (lowest speed). The rpm of the rooftop ventilator is measured by using the tachometer. The voltage and current produced by the generator are recorded. The experiment is repeated three times to get the average value and the experiment is repeated for medium speed and maximum speed of the table fan. The output of the generator is connected to the $1 \mathrm{~K} \mathrm{ohm}$ resistor to act as the load to the system. The generated voltage and current is measured through the resistor. The power is determined by multiplying the average value of voltage and current. Table 4 showing the voltage and power generated.

Table 4 Generated voltage by using the fan.

\begin{tabular}{cccc}
$\begin{array}{c}\text { Fan } \\
\text { Speed }\end{array}$ & $\begin{array}{c}\text { Rooftop } \\
\text { Ventilator }(\mathrm{RPM})\end{array}$ & $\begin{array}{c}\text { Average } \\
\text { Voltage }(\mathrm{V})\end{array}$ & $\begin{array}{c}\text { Power } \\
(\mathrm{mW})\end{array}$ \\
\hline 1 & 50.2 & 4.63 & 21.44 \\
2 & 58.3 & 5.00 & 25.00 \\
3 & 64.2 & 5.37 & 28.84
\end{tabular}

Fan speed 1 indicates the lowest fan speed, fan speed 2 indicates the medium fan speed and fan speed 3 indicates the highest fan speed. It shows that the lowest fan speed generated voltage at $4.63 \mathrm{~V}$ and produced $21.44 \mathrm{~mW}$ power with that fan speed. The highest fan speed can produce voltage $5.37 \mathrm{~V}$ and $28.84 \mathrm{~mW}$ power. The current increased when the speed of fan increased but in small value. The rotation of the ventilator depends on the amount of the air flow from the wind source. The higher the wind speed, the higher the power generated from the DC generator, as the fan speed increased from 1 to 3 , the average voltage generated increases linearly. The average current has similar characteristic with the average voltage.

The power generated can be determine by multiplying the value of average generated voltage with the average current. The power generated by the system increased gradually as the fan speed increased. The results show that the system is able to harvest the minimum power of $21.44 \mathrm{~mW}$ with the low wind speed. From the experiment conducted, the power generated can supply and light up $5 \mathrm{~V}$ LED bulb.

From the data obtained, it shows that the generated voltages are inconsistent due to air flow from the table fan and wind source from surrounding which can affect the air flow that pass through the ventilator blade. From the experiment, the rotation of the ventilator depends on the amount air flow from the wind sources.

The generated voltage is directly proportional to the speed of ventilator. Therefore, the experiment shows that the rooftop ventilator is effective to generate electricity because with the low speed of wind pass through the ventilator, the generator manages to produce a minimum 
voltage of $4.63 \mathrm{~V}$. However, the generated power produced is small because of some losses such as mechanical, electrical and magnetic losses occurred from the DC motor. Thus, these losses caused the efficiency of the DC motor to be reduced.

\section{Summary}

This paper discusses the development of a rooftop ventilator by using wind turbine technologies that can lead to energy harvesting and thus replaced the fossil fuels and natural gas. The important factors to determine the effectiveness of rooftop ventilator for electricity generation is the selection of the generator and the suitable gear ratios. From the performance of the system, it shows that the rooftop ventilator is effective to generate electricity because the selection of Permanent Magnet DC Motor which have the excellent starting torque managed to generate the minimum voltage of $4.63 \mathrm{~V}$ at low speed of wind and able to light up 5V LED bulb. The energy harvester system is expected to provide robust background in the various applications and possess sustainable in the future. Future work will be directed towards to store the generated energy into battery bank. The excess electricity generated from the generator can be store into the battery. A $12 \mathrm{~V}$ lead acid battery can be used to store the generated energy. The generated energy will be accumulated in the batteries so that the user can have a power supply all the time. The stored energy in the batteries also can be used as an alternative power supply to the user.

\section{Acknowledgement}

The authors would like to acknowledgement Khalid Latiff Holding Sdn. Bhd. in supporting this research work. This research study is funded by Research University Grant (Q.J130000.2523.15H88).

\section{References}

[1] M. M. Mansouri, M. Nayeripour, and M. Negnevitsky, "Internal electrical protection of wind turbine with doubly fed induction generator," Renew. Sustain. Energy Rev., vol. 55, pp. 840-855, 2016.

[2] H. C. Ong, T. M. I. Mahlia, and H. H. Masjuki, “A review on energy scenario and sustainable energy in Malaysia," Renew. Sustain. Energy Rev., vol. 15, no. 1, pp. 639-647, Jan. 2011.

[3] T. H. Oh, S. Y. Pang, and S. C. Chua, "Energy policy and alternative energy in Malaysia: Issues and challenges for sustainable growth," Renew. Sustain. Energy Rev., vol. 14, no. 4, pp. 12411252, 2010.

[4] S. M. Shafie, T. M. I. Mahlia, H. H. Masjuki, and A. Andriyana, "Current energy usage and sustainable energy in Malaysia: A review," Renew. Sustain. Energy Rev., vol. 15, no. 9, pp. 4370 4377, 2011.

[5] S. Farajzadeh, M. H. Ramezani, P. Nielsen, and E. S. Nadimi, "A testing procedure for wind turbine generators based on the power grid statistical model," Renewable Energy, 2017. [Online]. Available: http://dx.doi.org/10.1016/j.renene.2017.03.073.

[6] S. Dangeam, "An electric generator driven by a roof ventilator," vol. 9, pp. 147-158, 2011.

[7] M. Furuse, S. Fuchino, M. Okano, N. Natori, and H. Yamasaki, "Development of a cooling system for superconducting wind turbine generator," Cryogenics (Guildf)., vol. 80, pp. 199-203, 2016.

[8] M. M. Hossain and M. H. Ali, "Future research directions for the wind turbine generator system," Renew. Sustain. Energy Rev., vol. 49, pp. 481-489, 2015.

[9] S. T. Suganthi, D. Devaraj, K. Ramar, and S. Hosimin Thilagar, "An Improved Differential Evolution algorithm for congestion management in the presence of wind turbine generators," Renew. Sustain. Energy Rev., vol. 81, no. June 2017, pp. 635-642, 2018. 